\title{
Alveolar Ridge Augmentation with Titanium Mesh. A Retrospective Clini- cal Study
}

\author{
Pier P. Poli ${ }^{1}$, Mario Beretta ${ }^{2}$, Marco Cicciù $^{3, *}$ and Carlo Maiorana ${ }^{2}$ \\ ${ }^{I}$ Department of Oral Surgery and Implantology, University of Milan, School of Dentistry, IRCSS Cà Granda, Milan, \\ Italy \\ ${ }^{2}$ Department of Dental Implants. Maxillo-Facial and Odontostomatology Unit, Fondazione Cà Granda IRCCS Osped- \\ ale, Maggiore Policlinico. University of Milan, Milan, Italy \\ ${ }^{3}$ Department of Human Pathology, School of Dentistry. University of Messina, Policlinico G. Martino, Messina, Italy
}

\begin{abstract}
An adequate amount of bone all around the implant surface is essential in order to obtain long-term success of implant restoration. Several techniques have been described to augment alveolar bone volume in critical clinical situations, including guided bone regeneration, based on the use of barrier membranes to prevent ingrowth of the epithelial and gingival connective tissue cells. To achieve this goal, the use of barriers made of titanium micromesh has been advocated.

A total of 13 patients were selected for alveolar ridge reconstruction treatment prior to implant placement. Each patient underwent a tridimensional bone augmentation by means of a Ti-mesh filled with intraoral autogenous bone mixed with deproteinized anorganic bovine bone in a 1:1 ratio. Implants were placed after a healing period of 6 months. Panoramic x-rays were performed after each surgical procedure and during the follow-up recalls. Software was used to measure the mesial and the distal peri-implant bone loss around each implant. The mean peri-implant bone loss was $1.743 \mathrm{~mm}$ on the mesial side and $1.913 \mathrm{~mm}$ on the distal side, from the top of the implant head to the first visible boneimplant contact, at a mean follow-up of 88 months.

The use of Ti-mesh allows the regeneration of sufficient bone volume for ideal implant placement. The clinical advantages related to this technique include the possibility of correcting severe vertical atrophies associated with considerable reductions in width and the lack of major complications if soft-tissue dehiscence and mesh exposures do occur.
\end{abstract}

Keywords: Autogenous bone, bone augmentation, bone resorption, dental implants, guided bone regeneration, titanium me.

\section{INTRODUCTION}

The replacement of missing teeth with dental implants in the treatment of totally and partially edentulous jaws has become a reliable treatment. An adequate amount of bone for complete circumferential coverage of implant surfaces is essential to ensure the long-term success of implant restoration [1], as well as an adequate aesthetic outcome and a proper biomechanical support of the prosthesis [2]. Indeed, the minimum amount of bone seems to be $4 \mathrm{~mm}$ horizontally and $7 \mathrm{~mm}$ vertically ${ }^{1}$. If implant stability or appropriate positioning cannot be achieved, ridge augmentation must be performed before or during implant placement to overcome anatomic limitations of the residual jaw bone crest.

Techniques to improve bone volume of segmental defects in the atrophic or dysmorphic (post-oncological)

*Address correspondence to this author at the Department of Human Pathology, School of Dentistry. University of Messina, Policlinico G. Martino, Via Consolare Valeria, 98100 Me, Italy; Tel: +390902216911;

E-mail: acromarco@yahoo.it maxilla and mandible have been widely described. Splitting osteotomy [3], distraction osteogenesis [4, 5], guided bone regeneration with resorbable [6] and non-resorbable [7] membranes or Ti-mesh [8], and onlay block grafts taken from intraoral or extraoral sites [9], are the most commonly applied methods.

Regeneration of bone in conjunction with placement of oral implants, augmentation of resorbed alveolar ridges, and treatment of localized ridge defects, are quite common clinical situations that can be managed by means of a valuable technique first described in 1959 by Hurley et al., commonly known as guided bone regeneration (GBR), which was developed during experimental reconstructive surgery by Hurley to treat experimental spinal fusion [10] and then applied in oral surgery by Simion $M$ and Dahlin $C$ [1, 11]. This technique is based on filling the defect with bone grafts and/or bone substitutes, and covering the material with a membrane to prevent ingrowth of the epithelial and gingival connective tissue cells [12]. The tissue regeneration promoted allows healing of bony defects within a period of 6 to 10 months [13]. 
One of the most important aspects in obtaining results with this technique for lateral and vertical ridge augmentation is the creation and maintenance of a secluded space under the membrane. The development of this space is the prime determinant of the amount of newly formed bone [14]. It is indeed known that without a containment system, a collapse of soft tissues toward the defect can occur, leading to compression or displacement of the graft and consequent inability to achieve the desired results $[8,15]$. Several possibilities have been proposed in order to avoid membrane collapse and to increase regenerative capabilities of the bone in non space-making situations, such as reinforced e-PTFE membranes [1], or self- reinforced polyglycolide membranes [16], however even with miniscrews or pins to support them, lateral collapse [17]. Is possible. Furthermore other potential drawbacks include increased procedure time and cost, and above all, the risk of short-term membrane exposure [18]. As a possible alternative, the use of titanium micromesh barriers has been advocated to overcome these limitations.

Ti-meshes were first introduced for restoring large osseous maxillofacial defects [19] and were secondarily proposed for osseous restoration of deficient edentulous maxillary ridges [20]. The use of Ti-meshes was re-encouraged by von Arx et al. (1996), who presented 'the TIME technique', characterized by the use of microtitanium augmentation mesh specifically designed for augmentation of ridge defects. Von Arx et al. presented positive results for localized alveolar ridge augmentation prior [21] and simultaneously to implant placement [22].

Many bone substitutes, both synthetic (such as tricalcium phosphate, hydroxyapatite) and natural (such as coral, bovine or human bone) have been used as filling material. The results depend on the surgical technique and on the quality of the filling materials used, which give very variable results. Various authors consider the use of autogenous bone grafts for ridge augmentation to be the gold standard, due to the intrinsic osteogenic properties [18, 23]. Moreover, autogenous bone grafts are superior to other materials when primary osteogenesis and osteoinduction are considered [24, 25]. The surgical procedure involves autogenous bone harvested from chin, mandibular ramus and body or tuber maxillae. One of the major challenges however, is to minimize resorption of the grafted bone related to the fact that the sites for localized ridge augmentation are non-space-making defects, as they are not supported by bone walls [17]. When an extraoral site is involved, the large availability of bone makes overcontouring the most common way of dealing with the expected resorption of grafted bone [26, 27]. The situation is completely different in the case of intraoral harvesting, where the amount of bone available is limited. In order to overcome such limitations, the use of deproteinized anorganic bovine bone (DBBM) has been developed as a xenogeneic graft material that can be mixed with autogenous bone graft. The rationale of mixing autogenous bone with DBBM is to combine the scaffold properties of the xenograft with the osteogenic and osteoinductive properties of the autograft [28, 29].
The purpose of this study was to present the surgical and clinical implications of this technique over 13 cases, in which a Ti-mesh in combination with particulate autogenous bone graft mixed with DBBM (Bio-Oss ${ }^{\circledR}$, Geistlich, Wolhusen, Switzerland) were used to correct alveolar bone defects in both maxillary and mandibular arches, prior to implant placement, within a two-stage technique. Furthermore the peri-implant bone resorption was retrospectively evaluated at a mean follow-up of 88 months concerning 20 dental implants.

The positive results of the technique presented might lead clinicians to choose this surgical procedure to manage severe atrophic ridges and to give patients long-term aesthetics and functions. Therefore, the application of titanium meshes instead of non-absorbable membranes seems to promote soft tissue healing and better preservation of the bone graft. Moreover, using a mixture of biomaterial and autogenous bone reduces patient morbidity in the post-operative phase.

\section{MATERIALS AND METHODOLOGY}

A total of 13 patients were selected for alveolar ridge reconstruction treatment for implant placement purposes. A total of 20 dental implants were included in the study. Patients were healthy, non-smoking, with no systemic or local contraindication to intraoral surgery and implant placement. Included were patients that had maxillary or mandibular atrophy secondary to tooth loss, periodontal disease or trauma. All the patients were treated with the same surgical and prosthetic protocol.

\section{Initial Therapy}

Before surgery, partially edentulous patients received proper oral hygiene instructions and oral hygiene treatment. At the end of the initial therapy, before starting the surgical procedures, the patients demonstrated proper plaque control. All patients underwent radiographic exams prior to surgery (Figs. 1 and 2).

\section{Surgical Procedure}

\section{$\oint \oint$ Guided Bone Regeneration}

The surgical procedures were performed under local anaesthesia, including a pre-operative rinsing of the oral cavity with a $0.2 \%$ Chlorhexidine $\left(\right.$ Dentosan ${ }^{\circledR}$ ) antiseptic solution, and a perioral skin disinfection with benzalkonium chloride (Citrosil alcolico bruno, Esoform S.p.A., Rovigo, Italy). An antibiotic therapy begun $1 \mathrm{~h}$ before surgery was performed, with $2 \mathrm{~g}$ of amoxicillin clavulanate (Augmentin ${ }^{\circledR}$, GlaxoSmithKline, S.p.A., Verona, Italy). Local infiltration anaesthesia was used with mepivacaine chlorhydrate (Carboplyina 1:100000, Dentsply, Italy). Then $4 \mathrm{mg}$ of dexamethasone was injected into the muscles around the surgical site to reduce post-operative swelling.

A mid-crestal horizontal incision was made, with oblique releasing incisions where needed, in order to mobilize a full-thickness flap. The flap was carefully elevated from the palatal/lingual and buccal aspect of the alveolar ridge, isolating the neurovascular bundle in order to preserve 


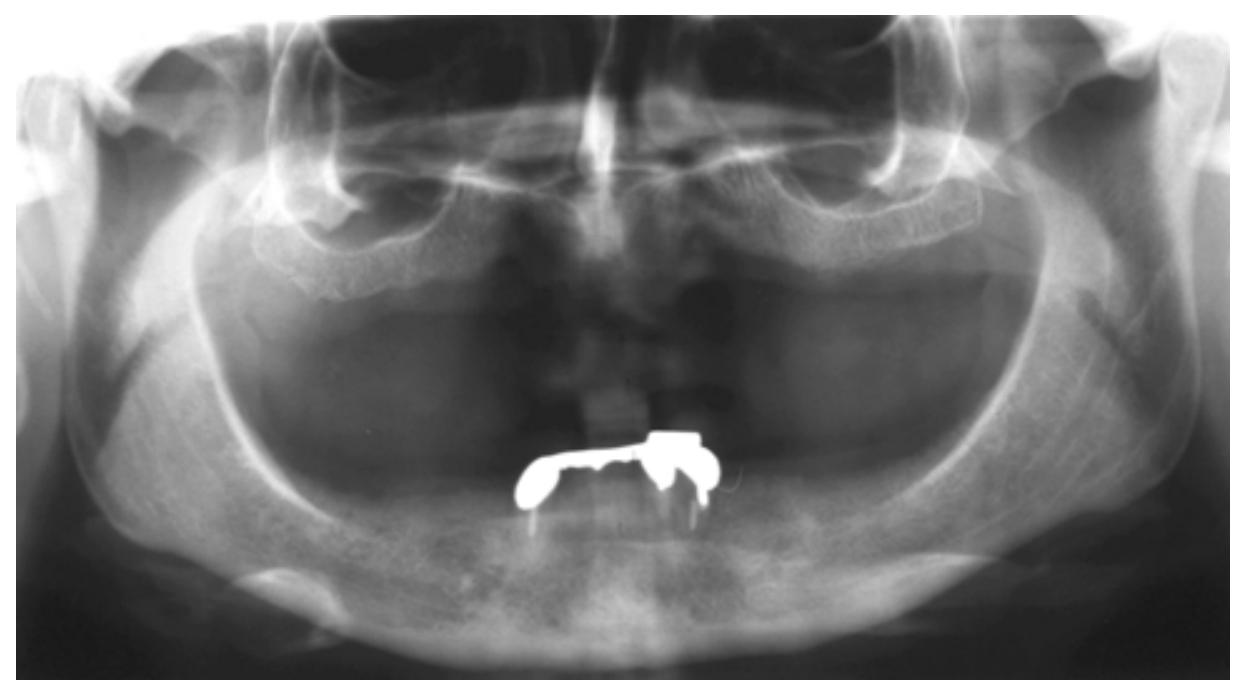

Fig. (1). Pre-operative orthopantomograph.

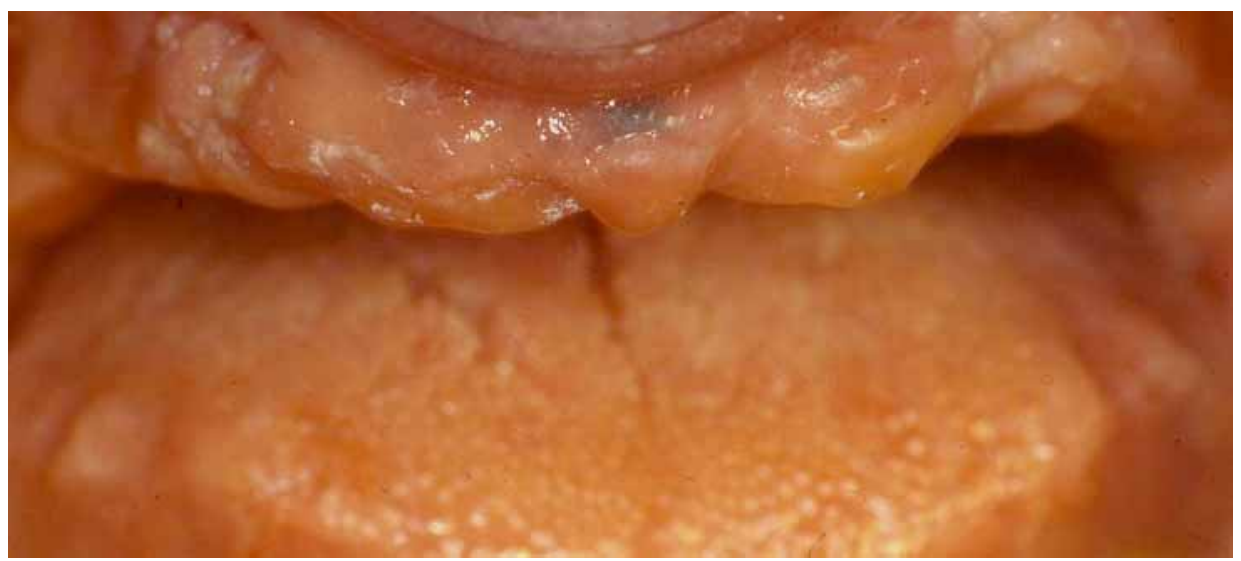

Fig. (2). Clinical situation before surgical procedures.

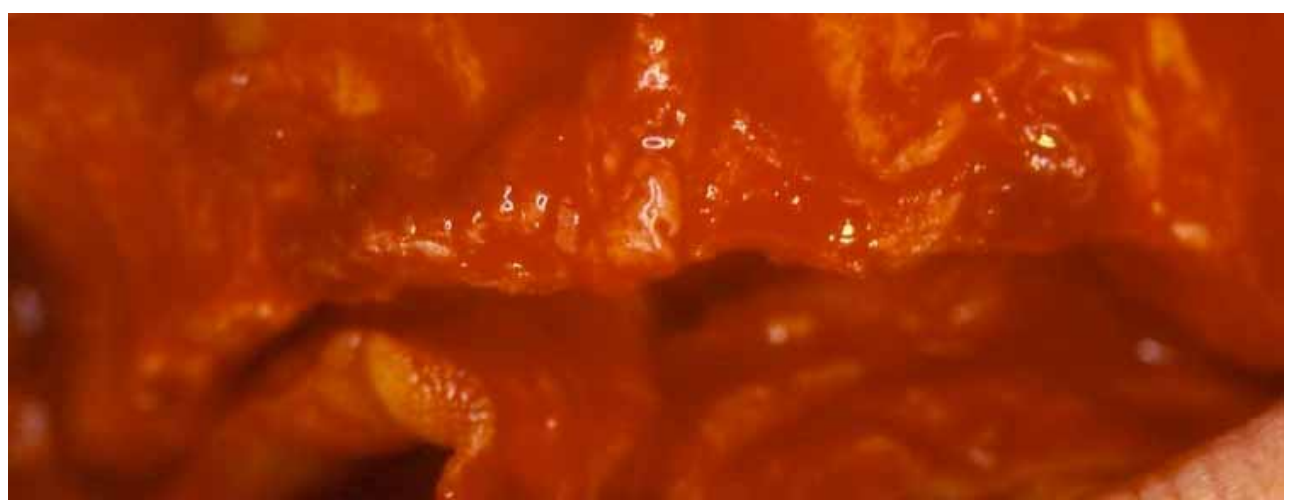

Fig. (3). Alveolar ridge pre-surgical anatomy after the reflection of a mucoperiosteal flap.

these vessels. All the granulation tissue was removed from the cortical bone. In all cases, intra-surgical evaluation confirmed a narrow alveolar ridge with insufficient crest width and height for ideal dental implant placement (Fig. 3). Perforations into the marrow space were performed using small round surgical burs to facilitate vascularization of the graft and cell colonization from the bone marrow. The autologous bone graft was harvested from intraoral regions, such as the tuber maxillae, the symphysis, the mandibular body and the retromolar pad region, using trephine burs and safe-scrapers.
A $0.2 \mathrm{~mm}$-thick Ti-mesh (KLS Martin, Tuttlingen, Germany) was trimmed and adapted to the surgical defect to create a proper bone contour. The Ti-mesh was shaped avoiding sharp edges in order to prevent soft tissue dehiscence or exposure. The minimum distance from the periodontium of the neighbouring teeth was $1.5 \mathrm{~mm}$ in order to prevent possible infiltrations through the gingival sulcus. The defects were filled with autogenous bone-chips mixed with DBBM (BioOss $^{\circledR}$, Geistlich, Wolhusen, Switzerland) in a $1: 1$ ratio, so as the deficiencies were completely filled, recreating the ideal 


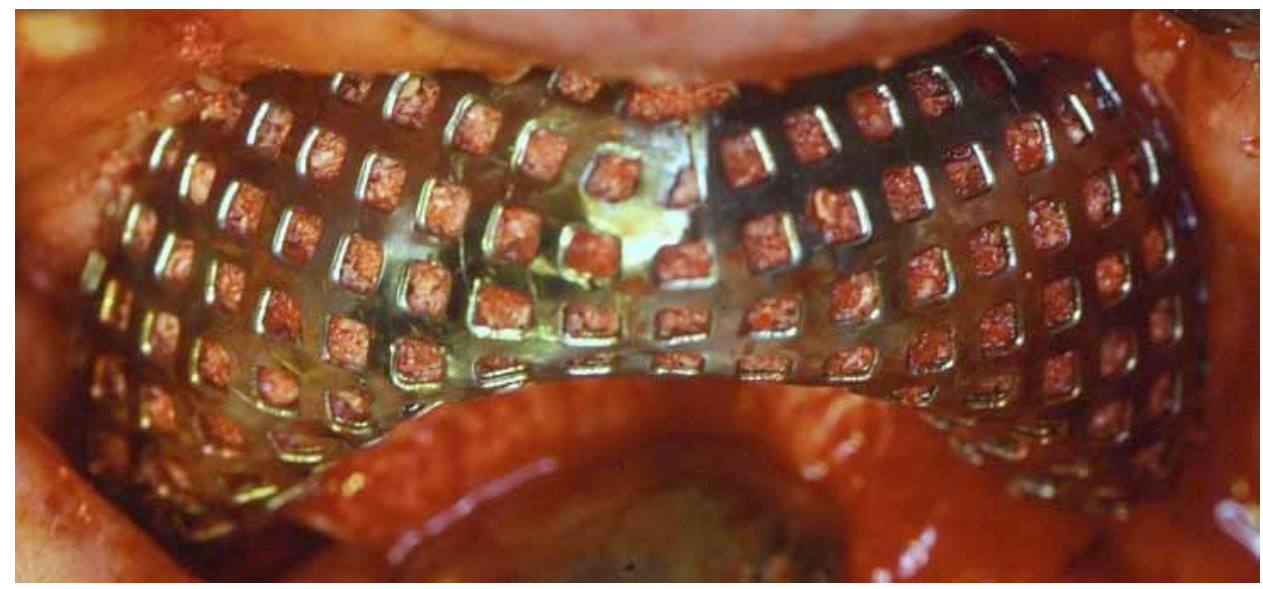

Fig. (4). Titanium mesh in situ, filled with a mixture of particulated autogenous bone and DBBM in a 1:1 ratio.

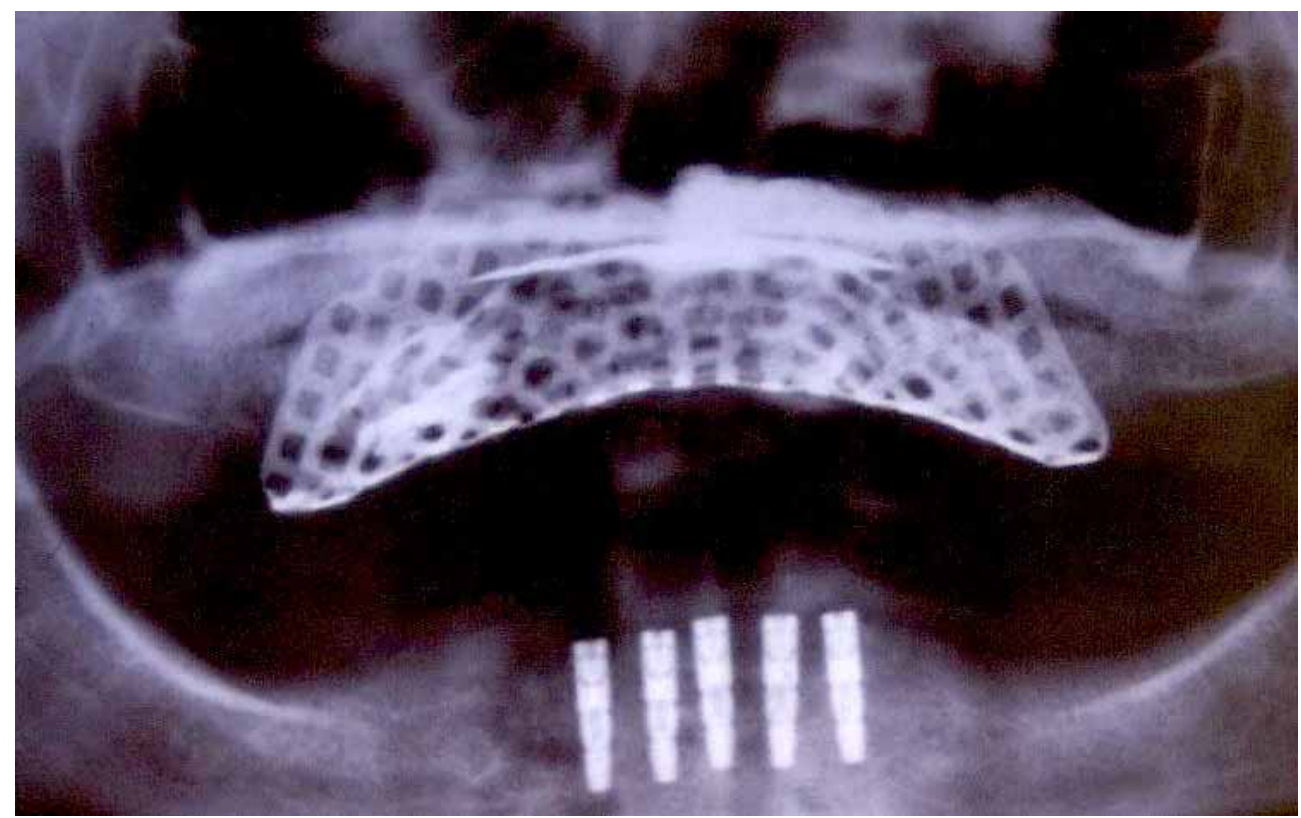

Fig. (5). Post-operative orthopantomograph.

amount of bone for subsequent implant placement. The Timesh was then placed over the graft and fixed to the palatal/lingual and buccal bony walls using cortical screws on each side to prevent any micro-movement (Fig. 4). Periosteal horizontal releasing incisions followed by upper traction were performed if necessary, to mobilize the buccal flap and obtain the passive closure essential to prevent dehiscence and Ti-mesh exposure. A double layer suture was applied with horizontal mattress and single stitches using a 3-0 Vicryl suture and a 2-0 and 4-0 silk (Ethicon Inc.) suture, to seal the overlapping periosteal portion of the palatal/lingual and buccal flaps.

Medication prescribed for post-operative use by the patient included $1 \mathrm{~g}$ of Augmentin ${ }^{\circledR}$ twice a day for 6 days and a $0.2 \%$ Chlorhexidine digluconate $\left(\right.$ Corsodyl $^{\circledR}$, GlaxoSmithKline, Verona, Italy) mouthwash rinse solution $1 \mathrm{~min}$ three times a day for the same period of time, starting the day after the surgery. An orthopantomograph was performed after the surgery (Fig. 5). The sutures were removed after 12 days. Two weeks later, temporary prostheses were applied for the healing period.

\section{$\oint \oint$ Implant Placement and Prosthetic Procedure}

After a 6-month healing period, each patient underwent the second surgical step to remove the Ti-mesh and place dental implants in a prosthetically guided position thanks to the newly formed bone. From a clinical and radiological point of view, no complications occurred during the 6-month healing period (Fig. 6).

Under local anaesthesia obtained with mepivacaine chlorhydrate injections, a horizontal incision was performed and a full thickness flap was reflected to uncover and remove the Ti-mesh.

During surgery, no clinical signs of inflammation around the Ti-mesh were found, and the grid was firmly 


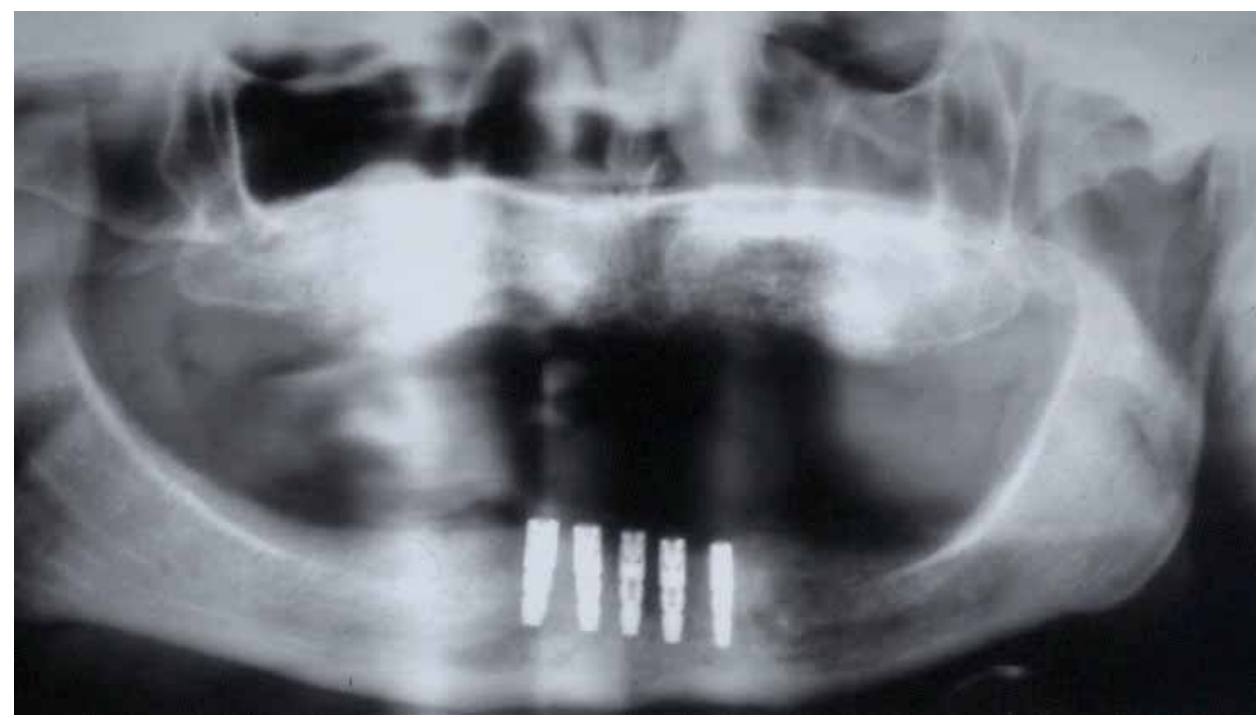

Fig. (6). Orthopantomograph after titanium mesh removal.

attached to the newly formed bone underneath. New bone formation was observed filling the entire space under the Timesh, as well as over the Ti-mesh in some areas.

The implant sites were prepared according to the manufacturer's instructions, and the fixtures were placed, achieving a proper primary stability. The flaps were then sutured (Figs. 7 and $\mathbf{8}$ ).

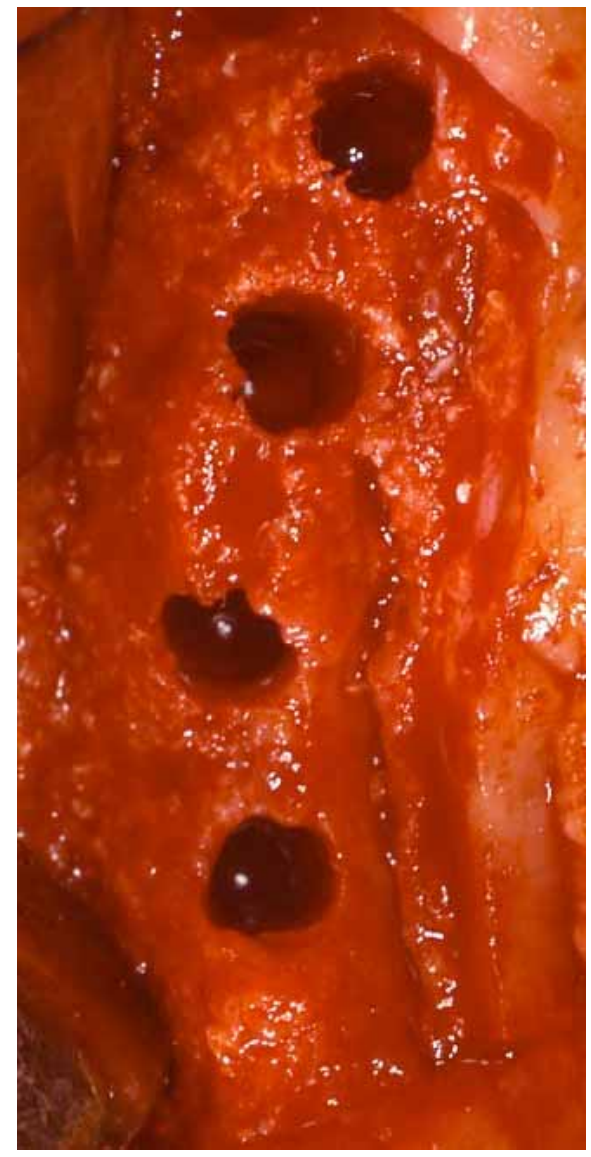

Fig. (7). Morphology of the newly formed bone in the right maxilla after a healing period of 6 months.

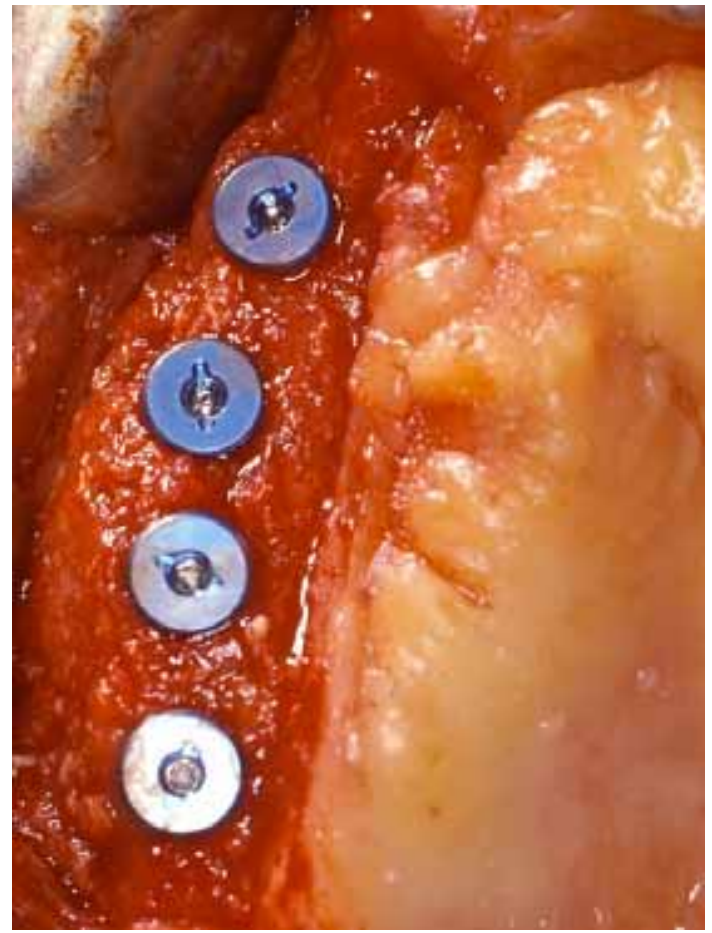

Fig. (8). Implants inserted in the right maxilla thanks to the amount of the regenerated bone.

After a healing period of 6 months, all implants achieved successful integration. Clinical evaluation showed no signs of complications and the panoramic radiographs showed no evidence of peri-implant radiolucency. A partial thickness flap was performed to uncover the implants and the healing abutments were placed (Fig. 9). In partially edentulous patients, temporary crowns were placed after a 3-week healing period and were left in situ for 6 months in order to modify and condition soft tissue contour and shape. All cases were restored with a fixed restoration to replace the missing teeth (Figs. 10 and 11). 


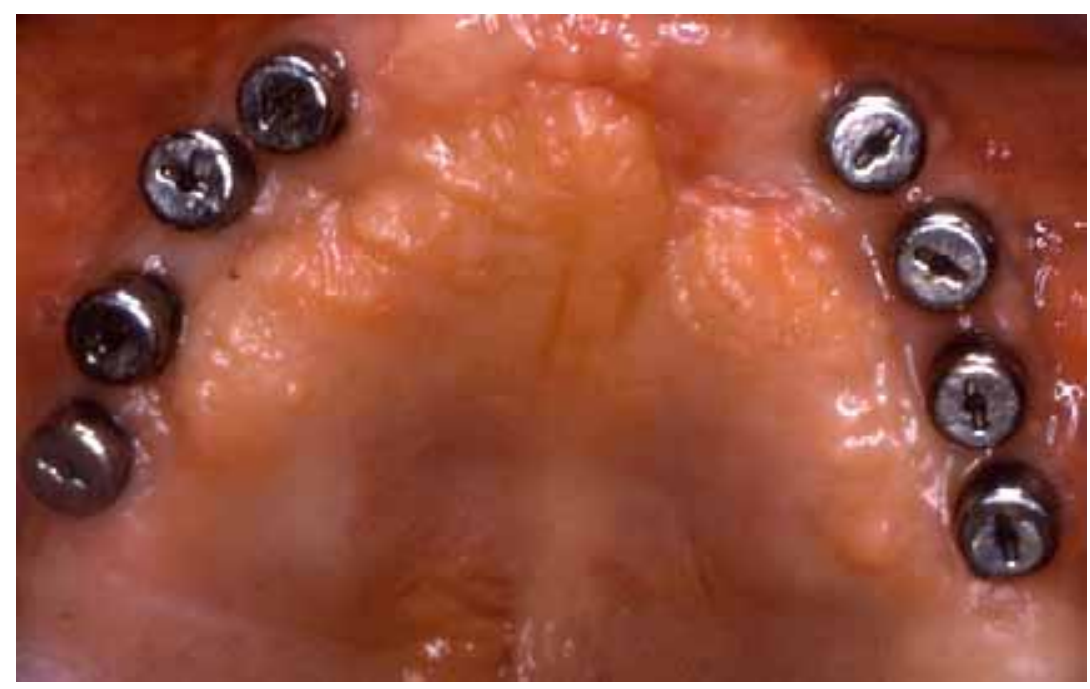

Fig. (9). Healing abutments connection.

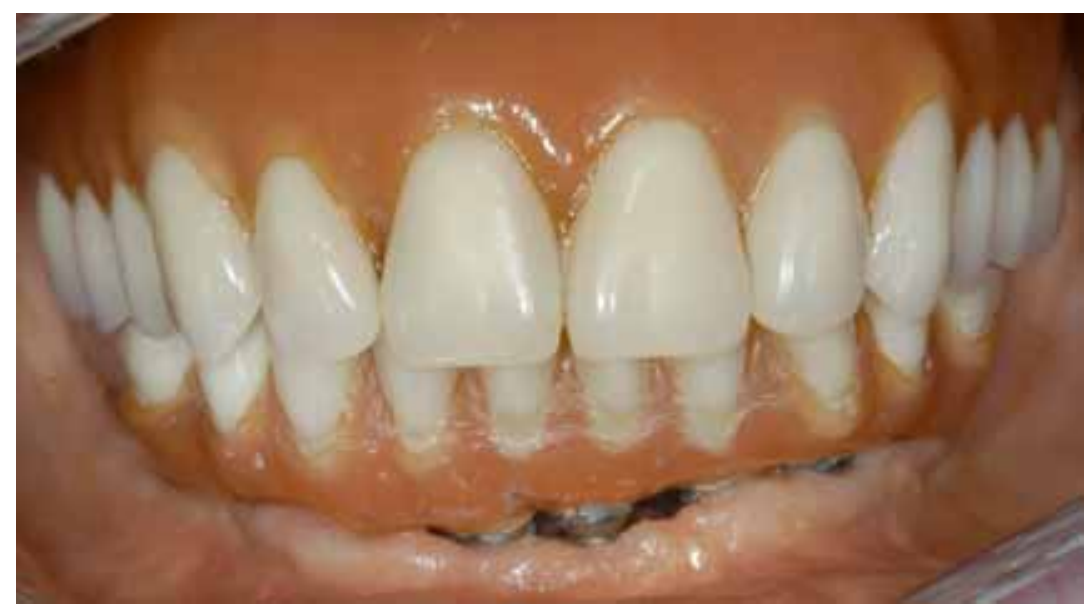

Fig. (10). Buccal view of the final prosthesis in situ.

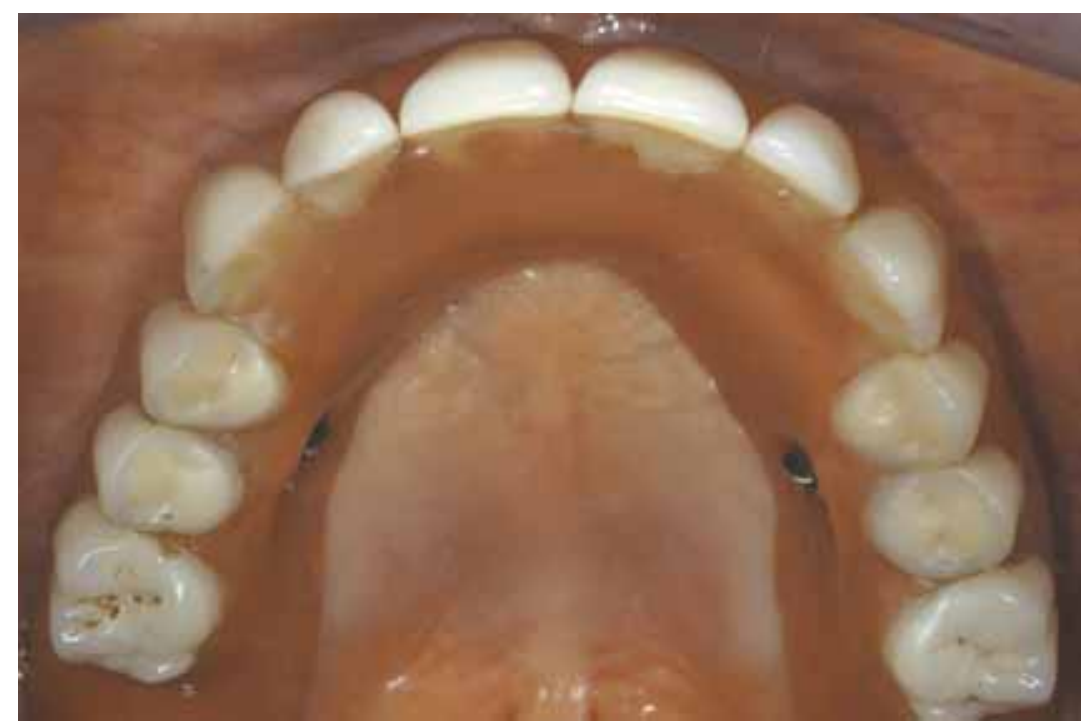

Fig. (11). Occlusal view of the final prosthesis in situ.

\section{Follow-up}

Clinical examination evaluated signs or symptoms of infection, loss of the grafted bone, dehiscence, and loss of dental implants. Radiological follow- up was performed by means of panoramic radiographs (Fig. 12). The patients had pre-operative panoramic radiographs, and post-operative radiographs at immediate post-operative follow-up, and at 3month, 5-month, 12-month and yearly follow-ups thereaf- 


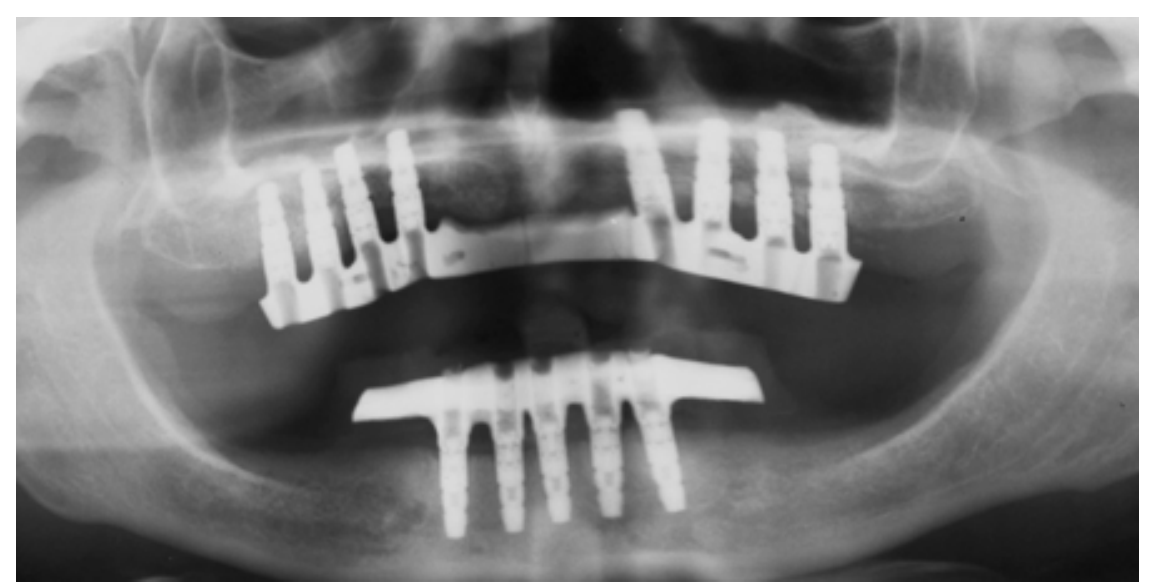

Fig. (12). Follow-up orthopantomograph.

ter. All radiographs were taken on the same machine and the radiographic exposure parameters remained unchanged for all the patients. The radiographic magnification factor was calculated based on the known length of the implant and the measurements obtained with the magnification scale were extrapolated to normal scale.

During the retrospective evaluation, a program (Image J, National Institute of Health, U.S.A.) was used to measure the mesial and the distal peri-implant bone loss around each implant. The values were obtained measuring the distance from the top of the implant head to the first visible boneimplant contact.

\section{RESULTS}

A total of 13 patients, 8 males and 5 females, underwent maxillary or mandibular alveolar ridge regeneration by means of Ti-mesh and particulate autogenous bone graft. Of these, 11 underwent maxillary reconstruction, and 2 underwent mandibular reconstruction. The source of bone grafts was the tuber maxillae in 8 cases, the symphysis in 2 cases, the mandibular ramus in 2 cases and the retromolar trigone region in 1 case. The length of the defects ranged from a minimum of one to a maximum of four teeth. The postoperative healing was uneventful in 12 patients $(92.30 \%)$, with neither major complications nor dropouts. In one patient $(7.69 \%)$, early Ti-mesh exposure after 4 months' healing was managed with chlorhexidine mouthwash rinse for 2 months. Closure of the soft tissue dehiscence occurred after the treatment.

At the re-entry procedure, the Ti-meshes appeared to be surrounded by a dense connective tissue without any clinical signs of inflammation. The devices appeared to adhere to the newly formed tissues, and, after their removal, a whitish soft tissue was present underneath; this tissue was carefully removed with a curette, and it was observed that the space under the grids was completely filled by a tissue with the macroscopic features of newly formed bone. The grafts appeared well maintained and incorporated into the native bone. From a clinical point of view, no residual bony defects were observed and a significant increase of the alveolar width and height was found in all patients, allowing the placement of submerged dental implants.
A total of 20 dental implants were placed in all patients, 16 in the maxilla and 4 in the mandible. The mean time between the reconstructive procedures and the re-entry surgery was 6 months. The success of the bone grafting procedure was $100 \%$ and, indeed, re-grafting was never required.

The number and positioning of the dental implants depended on the amount of regenerated bone and the next prosthetic restoration. In the mandibular bone, none of the areas with lower bone resistance were considered for implant placement in order to prevent possible fractures due to dental implant site preparation.

The retrospective evaluations (Table 1) showed a mean peri-implant bone loss of $1.743 \mathrm{~mm}$ (Standard Deviation [S.D.] 0.567) on the mesial side and

$1.913 \mathrm{~mm}$ (S.D. 0.710) on the distal side, obtained measuring the distance between the top of the implant head and the first visible bone-implant contact. The mean followup was 88 months with a range of 12 to 168 months. The survival and success rate (according to Albrektsson et al. parameters) at the most recent follow-up were 100\%. All cases restored with fixed restoration showed a good aesthetic result.

\section{DISCUSSION}

A sufficient volume and quality of alveolar bone must be present at potential implant recipient sites, so as to ensure a predictable long-term outcome in terms of aesthetics and function. During the past years, various techniques have been developed to restore an adequate bone volume when alveolar ridges are not suitable for the placement of dental implants. Several reconstructive procedures are available to increase both height and width. Grafting materials available include both particulate and block graft forms. In bone augmentation, it is ideal for bone-grafting materials to be resorbed at the same speed as bone formation, in order to be replaced by the bone. However, it is difficult to maintain an ideal bone shape when bone-grafting materials are resorbed faster than the rate of bone formation.

Autologous onlay bone grafts have been widely used and described; however when an external load is applied, these grafts have been shown to run into an extensive resorption 
Table 1. Retrospective evaluations. The mesial bone resorption (MBR) and the distal bone resorption (DBR) measured for each patient is showed, in addition to the site, the dimensions of the fixtures and the relative donor site.

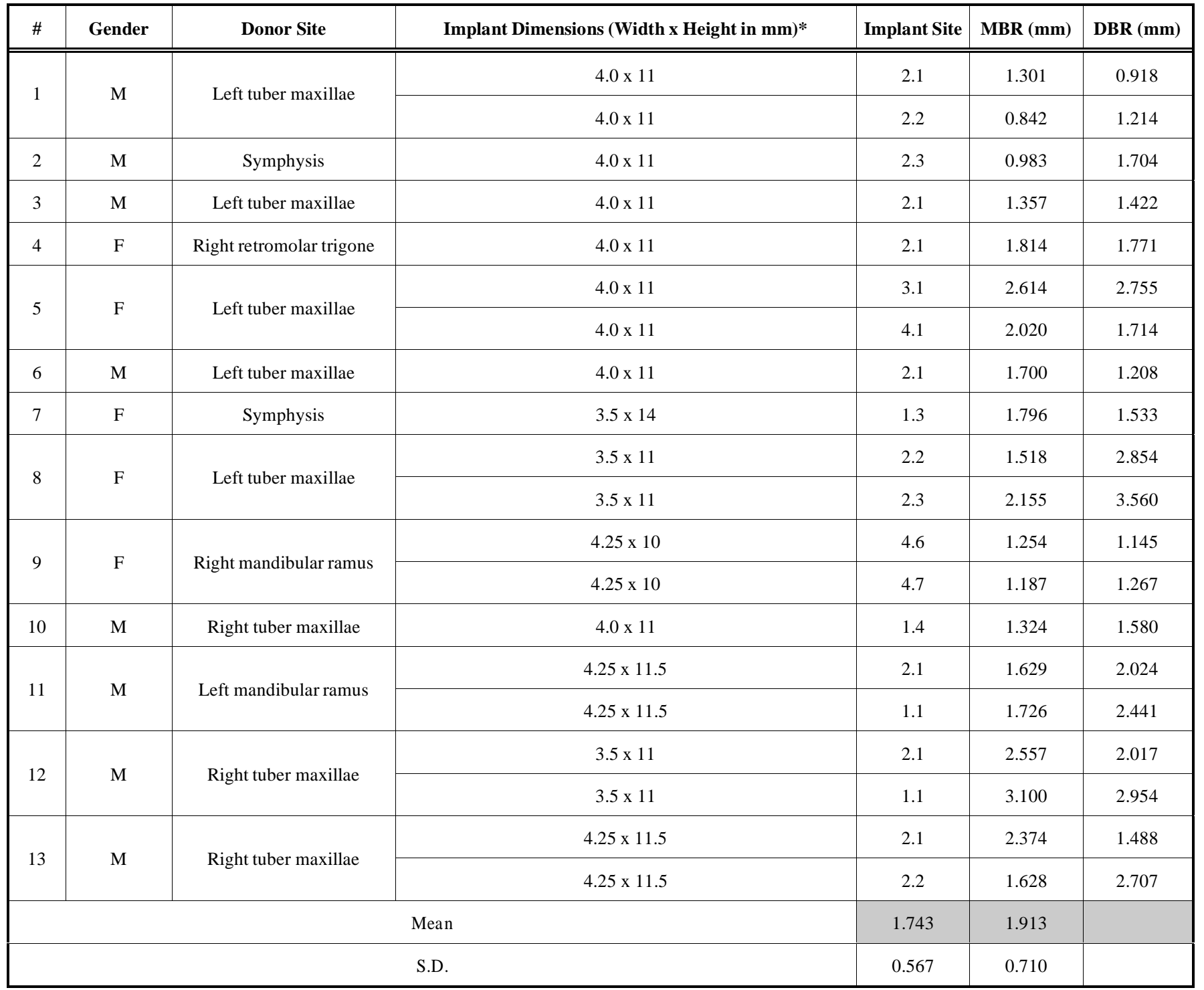

[30]. Better results are shown when autogenous bone graft is mixed with DBBM. Boyne et al., comparing autogenous iliac bone with a $1: 1$ autograft and DBBM mixture, found less bone height reduction in the mixed graft [31]. Simion et $a l$. in a clinical and histological study, pointed out that DBBM undergoes very slow resorption and substitution with new bone, supporting the use of DBBM in a $1: 1$ combination with autogenous bone chips as a composite graft for vertical ridge augmentation of atrophic ridges using GBR techniques [32].

Guided bone regeneration is currently used for the treatment of localized ridge augmentation, based on the concept of the membrane as a physical barrier designed to minimize resorption of the grafted bone. This is used to prevent the invasion of competing non-osteogenic soft tissue cells from the mucosa and to protect the autografts against resorption during healing.

There are two types of membrane: resorbable and nonresorbable. Resorbable membranes hold bone-grafting mate- rials in position and prevent soft tissue invasion. Buser et al. combined the membrane technique and bone grafts and reported less bone resorption, probably due to its protective effect during healing [33]. Antoun et al. compared of two bone augmentation techniques envisaging an onlay graft either alone or associated with a membrane and concluded that the membrane group experienced significantly less resorption than the graft-alone group [18]. This conclusion has been preliminary confirmed in a recent study by Cordaro et al., which revealed an over $40 \%$ decrease in vertical augmentation between bone grafting and implant insertion, 5-6 months later, when grafted sites were not protected [23]. It seems reasonable to protect the graft from moving around and become encapsulated in fibrous tissue. Considering the low risk of post-operative mucosal dehiscence, resorbable membranes are superior in terms of handling, however some complications have been described in the clinical application of the guided bone regeneration technique [34]: 1) soft tissue dehiscence with subsequent membrane exposure; 2) membrane displacement during wound 
closure; 3) lack of stiffness causing membrane collapse during healing and therefore reducing the space needed for bone regeneration; 4) complete blockage of the periosteal blood supply by ingrowth of the angiogenic cells, resulting in slow healing. The risk of premature exposure of expanded membranes is a disadvantage and, in fact, early membrane removal is associated with a smaller gain in bone volume [35]. The predictability of guided bone regeneration is significantly compromised by infection of membrane sites, and the retention of the shape cannot be anticipated [36]. Dahlin et al. reported that a guided bone regeneration technique should preferably be used in situations in which the prognosis could be enhanced by, but would not be dependent on, the use of a membrane [37].

The surgical technique of alveolar ridge augmentation for implant placement has been modified with the introduction of non-resorbable membrane, to avoid membrane collapse and increase regenerative capabilities of the bone in nonspace-making situations, thereby improving the treatment outcome and predictability of the procedure [1].

Non-resorbable membrane are used to provide shape and to maintain space over the defect during the time required. It has been shown that bone gain is maximal when the membrane remains in place during the entire healing period [38]. Titanium-reinforced non-resorbable membranes retain their three-dimensional shape with a specific height and width but with this technique there is also a risk of post-operative mucosal dehiscence as they impede the establishment of a proper vascular supply. Simion et al. in a clinical and histological study in humans, demonstrated that the use of titanium-reinforced e-PTFE membranes for vertical ridge augmentation resulted in incomplete bone regeneration underneath the membrane [1]. This is probably due to: 1) shrinkage of the blood clot underneath the membrane during the initial stage of healing; 2) entrapment of air underneath the membrane; 3) membrane micro-movement; 4) insufficient healing period.

In contrast non-resorbable titanium mesh is a metal laminate that can adopt a three-dimensional shape without blocking the blood supply from the bone and the mucosal sides thanks to the presence of pores in the mesh. In an experimental study in dogs using titanium membranes, Celletti et al. found that, at three weeks, all these membranes were slightly exposed [39], probably due to the fact that they used a membrane without pores. The presence of pores may facilitate nutrition and metabolic exchange. Confirming the fact, a recent study by Gutta et al. demonstrated that porous membranes facilitate greater bone regeneration compared with resorbable membranes. Therefore, the risk of complications such as mucosal dehiscence is lower compared with titanium-reinforced non-resorbable membranes, thanks to the high biocompatibility of the titanium mesh [40]. This statement finds validation in a study by Her et al., wherein they found a lower rate of exposure when titanium grids were adopted in comparison with e-PTFE membranes [41]. Another very important advantage is that this material tolerates exposure very well. Louis et al. demonstrated that, in spite of exposure of the membrane in 23 $(52 \%)$ of their patients treated with titanium mesh, only one patient had failure of the graft [42]. This result is confirmed by a study developed by Buser et al. in which they demonstrate that non-resorbable e-PTFE membrane barriers, when exposed, result in infection that can compromise the regenerative outcome of the treatment, as exposure will not heal spontaneously [33]. In contrast, exposure of the titanium mesh did not appear to affect the final outcome as the ridge was augmented to receive the implants needed in the desired position [43]. This finding agrees with the study by Maiorana et al., in which exposure of titanium mesh led to early graft resorption in the exposed area of about $15 \%$ to $25 \%$, but did not cause any significant complications or interfere with implant placement [44]. Regarding the thickness, it seems that $0.2 \mathrm{~mm}$ represents the right balance between the necessary stiffness for flap support and graft protection and the essential flexibility to reduce the risk of mucosa perforation and soft-tissue dehiscence, in accordance with Roccuzzo et al. [45].

A two-stage approach was used in our cases, with dental implants placed after bone augmentation and mesh removal. Bone chip grafts and cells in bone tissue were harvested from the tuber maxillae, the mandibular ramus, the symphysis and the retromolar trigone. After 6 months' healing, bone grafting had been replaced by new bone, suggesting the presence of abundant osteoblasts, growth factors, and cytokines in the blood at the site. DBBM chip grafts served as an osteoconductive scaffold for the deposition of bone matrix during healing and autogenous grafts proved to have osteoinductive properties with regard to osteogenic transfer, providing a lattice network for the osteoinduction or osteoconduction of new bone [46, 47]. With bone-chip graft application, osteoblasts and osteoblast precursor cells, as well as growth factors and bone inducing factors entrapped in the grafted bone matrix, may be transferred to the augmentation site, resulting in the activation of new bone formation. The newly formed bone obtained with a two-stage approach, responds to implant placement in a similar way to nonregenerated bone, i.e. it is capable of bearing and sustaining the functional load. However, these results cannot be compared with other studies in which a simultaneous approach was used as: 1) bone volumes to be regenerated are usually smaller in the simultaneous than in the staged procedure; 2 ) in the simultaneous approach, bone regeneration and implant osseointegration take place during the same period, whereas in the staged approach osseointegration takes place after osseointegration has occurred; 3 ) in the staged approach the impact of implant insertion into not yet fully matured bone might stimulate further new bone formation [22]. No inconveniences were observed during the healing of the soft tissues. As the space for the bone regeneration is one of the most critical factors in the success of the regenerative techniques, the primary closure of the mucoperiosteal flap had a relevant role in the protection of the blood clot and in the prevention of infection. With this surgical technique, a sufficient bone mass was achieved to facilitate implant placement in the desired corono-apical position and angulation. The overall clinical and radiographic results of the present study show a survival and success rate of $100 \%$ according to Albrektsson et al.'s proposed criteria [48], confirming the favourable results of previous clinical studies [22, 49-52] on implants placed in regenerated bone using titanium grids. Though these studies cannot be easily compared due to the 
different sizes of the alveolar defects augmented, the implant placement procedure (one- versus two-stage), the use of autogenous bone or bone substitutes, the types of membrane, and the implant system [53]. The positive results of the present study have confirmed that implants placed in bone regenerated by this augmentative technique can successfully withstand the functional demands of implant loading, comparable to the results obtained in cases of implant placement in native alveolar bone [53].

\section{CONCLUSION}

The clinical cases evaluated demonstrated a surgical technique which does not show resorption for a long period of time. The higher the stiffness of a material, the lesser the tendency to collapse, and titanium mesh has been shown to be rigid enough to prevent soft tissue collapse, thus maintaining a space for grafted bone. Furthermore in our cases, the need to adapt the barrier to the bone contours was not a problem. The titanium grids were ductile and easy to handle, and appeared to have excellent space-making capabilities, allowing the mesh to be bent, contoured, and adapted to any single bony defect. Moreover, the ridge could be augmented both vertically and horizontally. This technique may offer a predictable alternative and excellent results for the reconstruction of ridge deficiencies for implant placement without undergoing major resorption. In accordance with many authors [23, 27, 33], this clinical investigation suggests a delayed approach when using autogenous bone grafts, DBBM grafts and titanium implants for the reconstruction of an atrophic maxilla, in terms of the vascularization of the bone transplants, the quality of the bone grafts and the blood supply to soft tissue. The possible clinical advantages of this technique include: 1) applicability to severe vertical deficit associated with considerable reduction in width; 2) reduced total rehabilitation time; 3) no major complications if soft-tissue dehiscence and mesh exposures do occur, and 4) decreased risk of injuries to neurovascular bundle or sinus and/or fractures [45].

The results of this study concur with other previous reports of the success of this material. In addition, our evaluation shows that this material is also appropriate as a containment system in augmentation in partially dentate patients prior to dental implant placement.

\section{CONFLICT OF INTEREST}

The authors confirm that this article content has no conflict of interest.

\section{ACKNOWLEDGEMENTS}

The authors would like to acknowledge Dr. Emma Thornton for the final language revision of the present manuscript.

\section{REFERENCES}

[1] Simion M, Trisi P, Piattelli A. Vertical ridge augmentation using a membrane technique associated with osseointegrated implants. Int J Periodontics Restorative Dent 1994; 14: 497-511.
[2] Mish CE. Contemporary implant dentistry. St Louis: Mosby-Year Book 1993. pp. 427-31.

[3] Engelke WG, Diederichs CG, Jacobs HG. Alveolar reconstruction with splitting osteotomy and microfixation of implants. Int $\mathbf{J}$ Oral Maxillofac Implants 1997; 12: 310-6.

[4] Jensen OT, Cockrell R, Kuhike L, Reed C. Anterior maxillary alveolar distraction osteogenesis: a prospective 5-year clinical study. Int J Oral Maxillofac Implants 2002; 17: 52-68.

[5] Uckan S, Dolanmaz D, Kalayci A. Distraction osteogenesis of basal mandibular bone for reconstruction of the alveolar ridge. $\mathrm{Br} \mathrm{J}$ Oral Maxillofac Surg 2002; 40: 393-9.

[6] Brocard D, Duffort JF, Jacquet E, et al. Bioabsorbable materials for guided bone regeneration prior to implant placement and 7 year follow-up: Report of 14 cases. J Periodontol 2001; 72: 257-64.

[7] Jovanovic SA, Tinti C, Benfenati SP. Longterm evaluation of osseointegrated implants inserted at the time or after vertical ridge augmentation. A retrospective study on 123 implants with 1-5 year follow-up. Clin Oral Implants Res 2001; 12: 35-45.

[8] Buser D, Dula K, Hirt HP. Lateral ridge augmentation using autografts and barrier membranes: a clinical study with 40 partially edentulous patients. J Oral Maxillofac Surg 1996; 54: 203-9.

[9] Schwartz-Arad D, Levin L. Intraoral autogenous block onlay bone grafting for extensive reconstruction of atrophic maxillary alveolar ridges. J Periodontol 2005; 76: 636-41.

[10] Hurley L, Stinchfield F, Bassett A, Lyon W. The role of soft tissues in osteogenesis. An experimental study of canine spine fusions. J Bone Joint Surg Am 1959; 41 A: 1243.

[11] Simion M, Dahlin C, Trisi P, Piattelli A. Qualitative and quantitative comparative study on different filling materials used in bone tissue regeneration: a controlled clinical study. Int J Periodont Restor Dent 1994;14:198-215.

[12] Hurzeler MB, Einsele F, Leupolz M, Schmitz HJ, Strub JR Bone augmentation using a synthetic bone graft in dogs. J Oral Rehabilitat 1994; 21: 373-82.

[13] Assenza B, Leghissa GC. Rigenerazione ossea con Gore-Tex dopo impianti immediati post-estrattivi (Bony regeneration by Gore-Tex after immediate postextractive implants). Dentista Moderno 1990; 6: 1137-44.

[14] Jovanovic SA, Schenk RK, Orsini M, Kenney EB. Supracrestal bone formation around dental implants: an experimental dog study. Int J Oral Maxillofac Implants 1995; 10: 23-31.

[15] Donos N, Kostodopulos I, Karring T. Alveolar ridge augmentation using a resorbable copolymer membrane and autogenous bone grafts: an experimental study in the rat. Clin Oral Implants Res 2002; 13: 449-56.

[16] Ashammakhi N, Makela EA, Vihtonen K, Rokkanen P, Tormala P. Effect of self-reinforced polyglycolide membranes on cortical bone: an experimental study in rats. J Biomed Mater Res 1995; 29: 687-94.

[17] Buser D, Dula K, Belser UC, Hirt HP, Berthold H. Localized ridge augmentation using guided bone regeneration, II: surgical procedure in the mandible. Int J Periodont Restorative Dent 1995; 15: 11-29.

[18] Antoun H, Sitbon JM, Martinez H, Missika P. A prosective randomized study comparing two technique of bone augmentation: onlay graft alone or associated with a membrane. Clinical Oral Implants Res 2001; 12: 632-9.

[19] Boyne PJ. Restoration of osseous defects in maxillofacial casualties. J Am Dental Assoc 1969; 78: 767-76.

[20] Boyne PJ, Cole MD, Stringer D, Shafqat JP. A technique for osseous restoration of deficient edentulous maxillary ridges. J Oral Maxillofac Surg 1985; 43: 87-91.

[21] von Arx T, Hardt N, Wallkamm B. The TIME technique: A new method for localized alveolar ridge augmentation prior to placement of dental implants. Int J Oral Maxillofac Implants 1996; 11: 387-94.

[22] von Arx T, Wallkamm B, Hardt N. Localized ridge augmentation using a micro titanium mesh: A report on 27 implants followed from 1 to 3 years after functional loading. Clin Oral Implants Res 1998; 9(2): 123-30.

[23] Cordaro L, Sarzi Amadè D, Cordaro M. Clinical results of alveolar ridge augmentation with mandibular block bone grafts in partially edentulous patients prior to implant placement. Clin Oral Implants Res 2002; 13: 103-11.

[24] Goldberg VM, Stevenson S. Natural history of autografts and allografts. Clin Orthop 1987; 225: 7-16. 
[25] Williamson RA. Rehabilitation of the resorbed maxilla and mandible using autogenous bone grafts and osseointegrated implants. Int J Oral Maxillofac Implants 1996; 11: 476-88.

[26] ensen J, Sindet-Pedersen S, Oliver AJ. Varying treatment strategies for reconstruction of maxillary atrophy with implants: results in 98 patients. J Oral \& Maxillofac Surg 1994; 52: 210-16.

[27] Chiapasco M, Abati S, Romeo E, Vogel G. Clinical outcome of autogenous bone blocks or guided bone regeneration with e-PTFE membranes for the reconstruction of narrow edentulous ridges. Clin Oral Implants Res 1999; 10: 278-88.

[28] Misch CE, Dietsh F. Bone grafting materials in implant dentistry. Implant Dent 1993; 2: 158-67.

[29] Yildirim M, Spiekermann H, Handt S, Edelhoff D. Maxillary sinus augmentation with the xenograft Bio-Oss and autogenous intraoral bone for qualitative improvement of the implant site: a histologic and histomorphometric clinical study in humans. Int $\mathbf{J}$ Oral \& Maxillofac Implants 2001; 16: 23-33.

[30] Boyne PJ. Reconstruction of the Maxilla and Mandible. Quintessence, Inc, Hanover Park, IL 1997; pp 37-52.

[31] Boyne P. Comparison of Bio-Oss and other implant materials in the mainteinance of the alveolar ridge of the mandible in man. Internartional symposium on modern trends in bone substitutes, Lucerne 1990.

[32] Simion M, Fontana F, Raperini G, Maiorana C. Vertical ridge augmentation by expanded-polytetrafluoroethylene membrane and a combination of intraoral autogenous graft and deproteinized anorganic bovine bone (Bio Oss). Clin Oral Impl Res 2007; 18: 620-9.

[33] Buser D, Dula K, Hirt HP, Shenk RK. Lateral ridge augmentation using autografts and barrier membranes. J Oral Maxillofac Surg 1996; 54: 420-33.

[34] Buser D, Bragger U, Lang NP, Nyman S. Regeneration and enlargement of jaw bone using guided tissue regeneration. Clin Oral Implants Res 1990; 1: 22-32.

[35] Rominger JW, Triplett RG. The use of guided tissue regeneration to improve implant osseointegration. J Oral Maxillofac Surg 1994; 52: $106-12$.

[36] Simion M, Baldoni M, Rossi P, Zaffe D. A comparative study of the effectiveness of e-PTFE membranes with and without early exposure during the healing period. Int J Periodont Res Dent 1994; 14: 166-80.

[37] Dahlin C, Andersson L, Linde A. Bone augmentation at fenestrated implants by an osteopromotive membrane technique: A controlled clinical study. Clin Oral Implants Res 1991; 2:159-65.

[38] Lekholm U, Becker W, Dahlin C, et al. The role of early versus late removal of GTAM membrane on bone formation at oral implants placed into immediate extraction sockets. Clin Oral Implants Res 1993; 4: 121.

[39] Celletti R, Davarpanah M, Etienne D, et al. Guided tissue regeneration around dental implants in immediate extraction sockets: com- parison of e- PTFE and a new titanium membrane. Int J Periodontics Restorative Dent 1994; 14: 243-53.

[40] Gutta R, Baker RA, Bartolucci AA, Louis PJ. Barrier membranes used for ridge augmentation: is there an optimal pore size? J Oral Maxillofac Surg 2009; 67(6): 1218-25.

[41] Louis PJ, Gutta R, Said-Al-Naief, Bartolucci A. Reconstruction of the maxilla and mandible with particulate bone graft and titanium mesh for implant placement. J Oral Maxillofac Surg 2008; 66: 23545.

[42] Roccuzzo M, Ramieri G, Bunino M, Berrone S. Autogenous bone graft alone or associated with titanium mesh for vertical alveolar ridge augmentation: a controlled clinical trial. Clin Oral Implants Res 2007; 18: 286-94.

[43] Maiorana C, Santoro F, Rabagliati M, et al. Evaluation of the use of iliac cancellous bone and anorganic bovine bone in the reconstruction of the atrophic maxilla with titanium mesh: A clinical and histologic investigation. Int J Oral Maxillofac Implants 2001; 16(3): 427-32.

[44] Roccuzzo M, Ramieri G, Spada MC, Bianchi SD, Berrone S. Vertical alveolar ridge augmentation by means of a titanium mesh and autogenous bone grafts. Clin Oral Implants Res 2004; 15: 73-81.

[45] Burchardt H. The biology of bone graft repair. Clin Orthop1983; 174: $28-42$.

[46] Mellonig JT. Autogenous and allogenic bone grafts in periodontal therapy. Crit Rev Oral Biol Med 1992; 3: 333-52.

[47] Albrektsson T, Zarb G, Worthington P, Eriksson AR. The longterm efficacy of currently used dental implants: A review and proposed criteria of success. Int J Oral Maxillofac Implants 1986; 1: 11-25.

[48] Fugazzotto PA. Success and failure rates of osseointegrated implants in function in regenerated bone for 6 to 51 months: A preliminary report. Int J Oral Maxillofac Implants 1997; 12: 17-24.

[49] Nevins M, Mellonig JT, Clem DS III, Reiser GM, Buser DA. Implants in regenerated bone: Long-term survival. Int J Periodontics Restorative Dent 1998; 18: 34-45.

[50] Simion M, Jovanovic SA, Tinti C, Benfenati SP. Longterm evaluation of osseointegrated implants inserted at the time or after vertical ridge augmentation. A retrospective study on $123 \mathrm{im}$ plants with 1-5 year follow-up. Clin Oral Implants Res 2001; 12: 35-45.

[51] Brunel G, Brocard D, Duffort JF, et al. Bioabsorbable materials for guided bone regeneration prior to implant placement and 7-year follow-up: Report of 14 cases. J Periodontol 2001; 72: 257-64.

[52] Fiorellini JP, Nevins ML. Localized ridge augmentation/preservation. A systematic review. Ann Periodontol 2003; 8 : 321-7.

[53] Weber HP, Crohin CC, Fiorellini JP. A 5-year prospective clinical and radiographic study of non-submerged dental implants. Clin Oral Implants Res 2000; 11: 144-53.

Received: June 06, 2014

(C) Poli et al.; Licensee Bentham Open.

This is an open access article licensed under the terms of the Creative Commons Attribution Non-Commercial License (http://creativecommons.org/licenses/by-nc/3.0/) which permits unrestricted, non-commercial use, distribution and reproduction in any medium, provided the work is properly cited. 